\title{
Bioconversion of Gentiana scabra Bunge increases the anti-inflammatory effect in RAW 264.7 cells via MAP kinases and NF- $\kappa B$ pathway
}

\author{
Min-A Kim ${ }^{1} \cdot$ Han-Saem Lee ${ }^{1} \cdot$ So-Hyun Chon ${ }^{1} \cdot J$ eong-Eun Park ${ }^{1} \cdot$ Yu-Mi Lim ${ }^{1}$. \\ Eun-Jeong Kim ${ }^{1} \cdot$ Eun-Kyung Son ${ }^{1} \cdot$ Sang-Jun Kim ${ }^{2} \cdot$ Jai-Hyun So $^{1}$ if
}

Received: 3 December 2018 / Accepted: 8 January 2019 / Published Online: 31 March 2019

(C) The Korean Society for Applied Biological Chemistry 2019

\begin{abstract}
Mitogen-activated protein (MAP) kinases play an important role in cell growth and differentiation, as well as the modulation of proinflammatory cytokines. The objective of this study was to examine the increase in the anti-inflammatory effect of Gentiana scabra Bunge (GSB), due to bioconversion with the Aspergillus kawachii crude enzyme, via inhibition of the NF- $\kappa \mathrm{B}$ signaling and MAP kinase pathways in RAW 264.7 cells. The expression of inducible nitric oxide synthase (iNOS) and cyclooxygenase-2 in RAW 264.7 cells treated with the GSB ethyl acetate fraction bioconverted with $A$. kawachii crude enzyme (GE-BA), was dramatically suppressed as compared to GSB ethyl acetate fraction non-bioconverted with the A. kawachii crude enzyme (GE-UA). The phosphorylation of p38, extracellular signalregulated kinases, and inhibitory $\kappa \mathrm{B}$ in RAW 264.7 cells treated with GE-BA was further suppressed, as compared to exposure to GE-UA. Moreover, the mRNA expression of interleukin 6, interleukin 1-beta, and tumor necrosis factor- $\alpha$ was further suppressed by GE-BA, compared to GE-UA. Similarly, antioxidant activities, such as 2,2-diphenyl-1-picrylhydrazyl hydrate and 2,2'-azino-bis(3-ethylbenzothiazoline-6-sulphonic acid) radical scavenging activity, of GE-BA were further increased compared to GE-UA. These observations demonstrate that the anti-oxidant and anti-inflammatory activities of GSB ethyl acetate fraction increases as a result from bioconversion with the A. kawachii crude enzyme.
\end{abstract}

Jai-Hyun So $(\bowtie)$

E-mail: dukeny@nikom.or.kr

${ }^{1}$ National Development Institute of Korean Medicine, 94, Hwarang-ro, Gyeongsan, Gyeongsangbuk-do 38540, Republic of Korea

${ }^{2}$ Department of Natural Science, Republic of Korea Naval Academy, Kyungnam 645-797, Republic of Korea

This is an Open Access article distributed under the terms of the Creative Commons Attribution Non-Commercial License (http://creativecommons. org/licenses/by-nc/3.0/) which permits unrestricted non-commercial use, distribution, and reproduction in any medium, provided the original work is properly cited.
Keywords Anti-oxidant · Aspergillus kawachii · Gentiana scabra Bunge $\cdot$ Inflammation

\section{Introduction}

Inflammation is a protective response to tissue damage resulting from several factors such as infection and burn injury, and usually be associated with tumors, immune response and free radicals. Tissue injury leads to the release of pro-inflammatory mediators such as nitric oxide (NO), cytokines, and leukotrienes [1,2]. The response of chronic inflammatory results in the excessive releases of pro-inflammatory mediators such as interleukin 6 (IL-6), interleukin 1-beta (IL-1 $\beta$ ), and tumor necrosis factor- $\alpha$ (TNF- $\alpha$ ). Therefore, a disorder in the anti-inflammatory response may cause various diseases including cancer, atherosclerosis, and inflammatory bowel disease [1,3-5]. NO is produced by nitric oxide synthase (NOS) which converts L-arginine to L-citrulline and considered as a regulatory mediator of inflammation. NOS can be classified into constitutive NOS (cNOS) and inducible NOS (iNOS). A high NO concentration stimulates macrophages, which is associated with inflammatory responses and increases the expression of proinflammatory cytokines including iNOS and cyclooxygenase-2 (COX-2). Consequently, high NO levels cause inflammation and oxidative stress [6,7].

Overproduction of reactive oxygen species (ROS), free radicals related to oxidative stress and chronic inflammatory response is associated with damaged proteins, lipids, and nucleic acids. ROS, which includes the hydroxyl radical $(\mathrm{OH})$, hydrogen peroxide $\left(\mathrm{H}_{2} \mathrm{O}_{2}\right)$, and the superoxide anion $\left(\mathrm{O}_{2}\right)$, lead to inflammatory responses by inducing iNOS and COX-2 expression in addition to activating TNF- $\alpha$ and the nuclear transcription factor $\kappa \mathrm{B}(\mathrm{NF}-\kappa \mathrm{B})$ [8]. Hence, increased oxidative stress can cause various chronic diseases such as arteriosclerosis, diabetes mellitus, and Alzheimer's disease [9-11]. Nevertheless, consuming anti-oxidant substances 
can decrease NO and ROS via the mitogen-activated protein

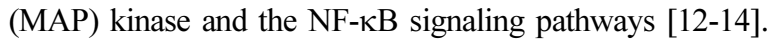

MAP kinases such as the extracellular signal-regulated kinase (ERK), c-Jun N-terminal kinase (JNK) and p38, are involved in cell proliferation and apoptosis [15]. MAP kinases are activated by oxidative stress $[16,17]$. In addition, $N F-\kappa B$ is a relevant transcription regulator of inflammatory genes associated with many diseases [18]. Thus, the intake of bioactive substances with anti-oxidant properties could play important roles in various human diseases.

Gentiana scabra Bunge (GSB), which belongs to the Gentianaceae family has been used in traditional medicine for its anti-inflammatory, anti-tumor, and anti-oxidant properties. The rhizomes and roots of GSB contain triterpenoids and secoiridoid glycosides. Moreover, GSB roots contain polysaccharides that have immunological effects, as well as anti-coagulant, anti-tumor, and anti-oxidant activity [19-23].

A bioconversion system called bioprocessing, biosynthesis or biocatalysis lead to the biotransformation of precursors to form new products using an enzyme's substrate specificity. Bioconversion has many advantages including mild reaction conditions, high specificity, and a low cost [24-26]. Furthermore, anti-oxidative and neuroprotective activities were increased by bioconversion than before it [27].

Therefore, this study was designed to investigate the elevated anti-oxidant and anti-inflammatory activities of a bioconverted GSB. Free radical scavenging activities of the bioconverted GSB were determined using the 2,2-diphenyl-1-picrylhydrazyl hydrate (DPPH) and 2,2'-azino-bis(3-ethylbenzothiazoline-6-sulphonic acid) (ABTS) assays. We determined the bioconverted GSB's inhibition of NO production, which was associated with $\mathrm{NOS}$ and COX-2 in LPS stimulated RAW 264.7 cells. Thus, the bioconverted GSB's anti-inflammatory effects were evaluated through MAP kinases, NF- $\kappa \mathrm{B}$, and pro-inflammatory cytokines.

\section{Materials and Methods}

\section{Preparation of crude enzyme extraction}

Ten grams of wheat bran with distilled water (DW, 1:1, w/v) was sterilized at $121^{\circ} \mathrm{C}$ for $15 \mathrm{~min}$. After sterilization, A. kawachii that was isolated from soybean [27] was inoculated in the sterilized wheat bran and fermented at $30{ }^{\circ} \mathrm{C}$ for three days. Afterward, 100 $\mathrm{mL}$ of $10 \mathrm{mM}$ sodium phosphate buffer $(\mathrm{pH} 7.0)$ was added to the fermented wheat bran and incubated at $4{ }^{\circ} \mathrm{C}$ for $18 \mathrm{~h}$. The mixture was filtered (filter paper, Advantec, Tokyo, Japan, No. 1) and centrifuged at $10,000 \mathrm{rpm}$ for $10 \mathrm{~min}$. The supernatant was used as an $A$. kawachii crude enzyme extract. This solution contained $0.276 \mathrm{U} / \mathrm{mL}$ ( $1 \mathrm{U}$ is defined as the enzyme activity needed to produce $1 \mathrm{mmol}$ of $\mathrm{p}$-nitrobenzene from $\mathrm{p}$-nitrophenyl- $\beta$-Dglucopyranoside per min) of $\beta$-glucosidase activity.

\section{Sample extraction and bioconversion}

Gentiana scabra Bunge (GSB) was purchased from Omniherb Co. (Daegu, Korea). Five hundred grams of GSB was extracted twice with $70 \%$ ethanol $(1: 10, \mathrm{w} / \mathrm{v})$ for $3 \mathrm{~h}$ using reflux extraction method. The extract was concentrated using a rotary vacuum evaporator (EYELA, N-1110, Tokyo, Japan) at $40{ }^{\circ} \mathrm{C}$. After concentration, the extract was dissolved in DW $(10: 1, \mathrm{v} / \mathrm{w})$ prior to the bioconversion step. Bioconversion was carried out through an $A$. kawachii enzymatic treatment $(0.260 \mathrm{U} / \mathrm{mL})$ [27]. Briefly, the extract solution was incubated with an $A$. kawachii crude enzyme extract $(1: 1, \mathrm{v} / \mathrm{v})$ at $30^{\circ} \mathrm{C}$ for $18 \mathrm{~h}$ and fractionated sequentially in $n$-hexane (He), ethyl acetate (EtOAc), and $n$ butanol $(\mathrm{BuOH})$. The $A$. kawachii crude enzyme was inactivated by autoclaving for the control group. The fractions were concentrated using a rotary vacuum evaporator and stored at -20 ${ }^{\circ} \mathrm{C}$ before analysis.

\section{UPLC chromatogram}

UPLC chromatogram was conducted using Waters ACQUITY Ultra Performance LC systems (Waters, Milford, MA, USA), on an ACQUITY UPLC CSH ${ }^{\mathrm{TM}} \mathrm{C} 18$ column $(1.7 \mu \mathrm{L}, 2.1 \times 100 \mathrm{~mm})$. An injection volume was $2 \mu \mathrm{L}$ and a flow rate $0.3 \mathrm{~mL} / \mathrm{min}$ were used. The mobile phase was filtered through a nylon membrane filter $(0.45 \mu \mathrm{m})$. The mobile phase consisted of (A) $0.1 \%$ formic acid in DW and (B) $0.1 \%$ formic acid in methanol. The gradient condition was as follows: initial gradient $0 \% \mathrm{~B}(0 \mathrm{~min})$ to $100 \%$ B (0-10 min). UPLC chromatograms were detected at $254 \mathrm{~nm}$.

\section{Evaluation of anti-oxidant activity}

The antioxidant activity was determined using DPPH and ABTS radical scavenging activity assays. The DPPH assay was performed according to the method of Blois [28]. Briefly, $2 \mu \mathrm{L}$ of sample was mixed with $190 \mu \mathrm{L}$ of $150 \mathrm{mM}$ DPPH solution and 8 $\mu \mathrm{L}$ of DMSO. The solution was incubated in the dark at $37^{\circ} \mathrm{C}$ for $30 \mathrm{~min}$ and measured at $517 \mathrm{~nm}$ (Spectrostar Nano, BMG Labtech, Australia).

ABTS was determined using the colorimetric method with some modifications [29]. $7 \mathrm{mM}$ ABTS solution was mixed with $2.45 \mathrm{mM}$ potassium persulfate $(2: 1, \mathrm{v} / \mathrm{v})$ and allowed to react for 12-16 h. The reaction solution $\left(\mathrm{ABTS}^{+}\right.$) was diluted using $5 \mathrm{mM}$ phosphate buffer ( $\mathrm{pH} 7.4$ ) to an absorbance of $0.7 \pm 0.02$ at 734 $\mathrm{nm}$. One hundred and ninety-eight micro liters of the dilution solution and $2 \mu \mathrm{L}$ of sample were incubated for $1 \mathrm{~min}$ and the absorbance was detected at $734 \mathrm{~nm}$ using a microplate reader. DPPH and ABTS radical scavenging activity was calculated using the following equation:

Radical scavenging activity (\%): (1-Abs sample $\left./ \mathrm{Abs}_{\text {blank }}\right) \times 100$

Cell culture and cell viability assay

Raw 264.7 cells, mice monocyte macrophage cell line, were 
obtained from the Korean Cell Line Bank (KCLB, Seoul, Korea) and grown in Dulbecco's modified Eagle's medium (DMEM, Welgene, Daegu, Korea) with $10 \%$ inactivated fetal bovine serum (FBS, Gibco BRL, Grand Island, NY, USA) and 1\% penicillinstreptomycin (P/S, Gibco BRL, Grand Island, NY, USA) at $37{ }^{\circ} \mathrm{C}$ and $5 \% \mathrm{CO}_{2}$.

Cell viability was measured using an 3-(4,5-dimethylthiazol-2yl)-2,5-diphenyl tetrazolium bromide (MTT) assay. RAW 264.7 cells were seeded in $96-$ well plates at a density of $5 \times 10^{4}$ cells/well and incubated for $24 \mathrm{~h}$ in a DMEM media supplemented with $10 \% \mathrm{FBS}$ and $1 \% \mathrm{P} / \mathrm{S}$. After $24 \mathrm{~h}$, cells were treated with various sample concentrations $(10,25,50,100 \mathrm{ppm})$ for $1 \mathrm{~h}$ and then stimulated with $1 \mu \mathrm{g} / \mathrm{mL}$ of lipopolysaccharide (LPS, Sigma, St. Louis, MO, USA) from E. coli 0111:B4 for an additional $24 \mathrm{~h}$. After the $24 \mathrm{~h}$ incubation with LPS, the cells were added to 100 $\mu \mathrm{L}$ of the MTT solution in each well and allowed to incubate for $4 \mathrm{~h}$. The amount of MTT-formazan crystals was measured at 575 $\mathrm{nm}$ using a microplate reader [30]. Cell viability was expressed as percentages of the control group that was untreated with LPS.

\section{Nitric oxide production assay}

Nitric Oxide (NO) production was measured as previously described using Griess reagents [30]. In brief, RAW 264.7 cells $\left(5 \times 10^{4}\right.$ cells/well) were incubated for $24 \mathrm{~h}$ and treated with the sample $1 \mathrm{~h}$ before LPS $(1 \mu \mathrm{g} / \mathrm{mL})$ stimulation. After an additional $24 \mathrm{~h}$ incubation, $100 \mu \mathrm{L}$ of the culture media supernatants were reacted with $100 \mu \mathrm{L}$ of Griess reagents ( $1 \%$ sulfanilamide $/ 0.1 \%$ $\mathrm{NED}$ in $5 \% \mathrm{H}_{3} \mathrm{PO}_{4}$ ) for $10 \mathrm{~min}$. NO production was determined at $540 \mathrm{~nm}$.

\section{Western blot analysis}

The RAW 264.7 cells $\left(5 \times 10^{6}\right.$ cells/well) were cultured in a 100 $\mathrm{mm}$ dish and incubated for $24 \mathrm{~h}$ prior to being treated with various concentrations of the sample $(50,100 \mu \mathrm{g} / \mathrm{mL})$ and with LPS $(1 \mu \mathrm{g} / \mathrm{mL})$ stimulation for $1 \mathrm{~h}$. After incubation for $24 \mathrm{~h}$, the cells were washed with PBS (Gibco BRL, Grand Island, NY, USA), harvested and centrifuged at $12,000 \mathrm{rpm}$ for $1 \mathrm{~min}$ at $4{ }^{\circ} \mathrm{C}$. After centrifugation, the supernatant was discarded and $400 \mu \mathrm{L}$ of proprep protein extraction solution (iNtRON Biotechnology Inc., Seoul, Korea) was added. Protein extraction was undertaken at $-20{ }^{\circ} \mathrm{C}$ for $30 \mathrm{~min}$ and centrifuged at $12,000 \mathrm{rpm}$ for $10 \mathrm{~min}$ at $4{ }^{\circ} \mathrm{C}$. A BCA protein assay kit (Thermo, Meridian Rd, Rockford, USA) was used to determine the amount of protein in the supernatant. Total protein concentrations $(20 \mu \mathrm{g})$ were stored -20 ${ }^{\circ} \mathrm{C}$ before use. The extracted proteins were electrophoretically separated on 10\% SDS-PAGE (polyacrylamide gels) and transferred to PVDF membranes (Bio-Rad, Indianapolis, IN, USA). The membranes were blocked with 5\% skim milk at room temperature for $1 \mathrm{~h}$. Primary antibodies such as $\beta$-actin, iNOS,

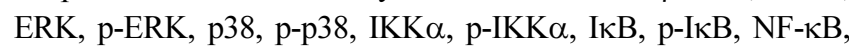
and JNK (Cell Signaling Technology, Boston, MA, USA) as well as COX-2 (Abcam, Cambridge, MA, USA) were diluted 1:1,000 in bovine serum albumin (BSA, Amresco, Solon, OH, USA) and incubated for $1 \mathrm{~h}$ at room temperature with gentle shaking. After washing with TBST, secondary antibodies (anti-mouse 1:1,000, anti-rabbit 1:1,000, v/v) that were purchased from Santa Cruz (Santa Cruz Biotechnology, Dallas, TX, USA) were added to the membrane for incubating at room temperature for $1 \mathrm{~h}$. The membranes were washed again with tris-buffered saline/tween 20 (TBST). Protein bands were detected using enhanced chemiluminescence (ECL) western substrate solution (EZ west Lumi plus, ATTO, Tokyo, Japan) and measured by Image J 1.48v (NIH, Bethesda, NC, USA) [31,32].

\section{Nuclear and cytoplasmic protein extraction}

Cells were cultured as previously described in western blot analysis. Nuclear and cytoplasmic protein extraction were undertaken using nuclear extraction kit (Abcam, ab113474, New Territories, Hong Kong) according to the manufacturers protocol. In brief, cells were washed with PBS buffer twice and collected using a scraper. The cells were subsequently centrifuged at $1,000 \mathrm{rpm}$ for $5 \mathrm{~min}$. After discarding the supernatant, $100 \mu \mathrm{L}$ of a $1 \mathrm{X}$ pre-extraction buffer was added and incubated on ice for $10 \mathrm{~min}$. The extraction was vortexed vigorously for $10 \mathrm{sec}$ and centrifuged at 12,000 rpm for $1 \mathrm{~min}$. The supernatant was used as the cytoplasmic extract and the pellet was used as the nuclear pellet. The cytoplasmic extract was quantified using the BCA protein assay kit. An extraction buffer containing DTT and PIC (1:1,000, v/v) was added to the pellet prior to it being incubated on ice for $15 \mathrm{~min}$ with vortexing every $3 \mathrm{~min}$. After centrifugation at 14,000 rpm for $10 \mathrm{~min}$ at $4{ }^{\circ} \mathrm{C}$, the supernatant was quantified using the BCA protein assay kit. The nuclear and cytoplasmic protein extractions were stored in $-20{ }^{\circ} \mathrm{C}$ until analysis [33].

\section{RNA preparation and reverse transcriptase (RT)-PCR}

Cells were cultured at a density of $1 \times 10^{6}$ cells/well in a 6-well plate and treated as previously described. Total RNA was isolated using a Trizol reagent (Ambion, Austin, TX, USA). Briefly, $1 \mathrm{~mL}$ of Trizol was added to the cells and incubated at room temperature for $5 \mathrm{~min}$. Afterward, $250 \mu \mathrm{L}$ of chloroform was added and centrifuged at $10,000 \mathrm{rpm}$ for $5 \mathrm{~min}$ at $4{ }^{\circ} \mathrm{C}$. The supernatant was added to $550 \mu \mathrm{L}$ of isopropanol and incubated at room temperature for $5 \mathrm{~min}$. This solution was centrifuged again at 13,200 rpm for $20 \mathrm{~min}$ at $4{ }^{\circ} \mathrm{C}$, and the supernatant was removed and added to $700 \mu \mathrm{L}$ of $75 \%$ ethanol in DEPC water. The solution was centrifuged again at 9,500 $\mathrm{rpm}$ for $5 \mathrm{~min}$ at $4{ }^{\circ} \mathrm{C}$ after which the supernatant was discarded. Total RNA concentration was dissolved in DEPC water and mixed with PrimeScript ${ }^{\mathrm{TM}} 1 \mathrm{st}$ strand cDNA synthesis kit (Takara, Tokyo, Japan) at a 1:20 (v/v) dilution. The mixture was incubated at $65{ }^{\circ} \mathrm{C}$ for $5 \mathrm{~min}$ and afterward kept on ice. A polymerase chain reaction (PCR, Analytik, Jena, Germany) was subsequently performed at $42{ }^{\circ} \mathrm{C}$ for $45 \mathrm{~min}$ and $95^{\circ} \mathrm{C}$ for $5 \mathrm{~min}$. Reverse transcriptase (RT)-PCR was performed using a mixture of cDNA, RT-PCR premix and 
antisense primers under the following conditions: 30 cycles of $98^{\circ} \mathrm{C}$ for $10 \mathrm{~min}, 55^{\circ} \mathrm{C}$ for $30 \mathrm{sec}, 72^{\circ} \mathrm{C}$ for $1 \mathrm{~min}$. The PCR products were seperated using electrophoresis with $1.0 \%$ agarose gels at 100 volts for $30 \mathrm{~min}$. $\beta$-Actin, iNOS, COX-2, IL-6, IL-1 $\beta$, and TNF- $\alpha$ were detected using previously described primer pairs. The $\beta$-actin primers were 5'-GTGGGCCGCCCTAGGCACCAG3' (sense) and 5'-GGAGGAAGAGGATGCGGCAGT-3' (antisense), the iNOS primers were 5'-CCCTTCCGAAGTTTCTGGCAGCA GC-3' (sense) and 5'-GGCTGTCAGAGCCTCGTGGCTTTGG-3' (antisense), the IL-6 primers were 5'-GTACTCCAGAAGACCAG AGG-3' (sense) and 5'-TGCTGGTGACAACCACGGCC-3' (antisense), the IL- $1 \beta$ primers were 5 '-CAGGATGAGGACATGA GCACC-3' (sense) and 5'-CTCTGCAGACTCAAACTCCAC-3' (antisense) [34].

\section{Statistical analysis}

Data were expressed as means \pm standard deviation (SD). Statistical analyses were conducted using Student's T-test and $p<0.05$ was considered statistically significant.

\section{Results}

\section{UPLC chromatogram}

The UPLC profile of the GSB extracts before and after bioconversion is shown in Fig. 1A slight difference was observed between the hexane fractions of $A$. kawachii-bioconverted GSB (GH-BA, Fig. 1B) and A. kawachii-untreated GSB (GH-UA, Fig. 1A). In addition, no distinct change was seen between the $\mathrm{BuOH}$ fractions of A. kawachii bioconverted GSB (GB-BA Fig. 1F) and A. kawachii-untreated GSB (GB-UA, Fig. 1E). However, the ethyl acetate fraction of the A. kawachii-bioconverted GSB showed unknown peaks with remarkable increments (GE-BA, Fig. 1D), as compared to the ethyl acetate fraction of the A. kawachii-untreated GSB (GE-UA, Fig. 1C).

\section{Anti-oxidant activity}

Due to the ease of protocols involved, the DPPH and ABTS free radical scavenging activities are widely used in anti-oxidant experimental assays [35]. The free radical scavenging effects of GSB were investigated with the DPPH and ABTS assays, and results are shown in Fig. 2. GSB showed similar free-radical scavenging activity patterns under both DPPH and ABTS assays. Specifically, the free-radical scavenging activity of all the GE-BA concentrations increased remarkably as compared to the GE-UA concentrations, while the other fractions showed no difference between the bioconverted and bio-unconverted extracts. DPPH radical scavenging activity of 200 ppm GE-BA was $87.32 \pm 0.75 \%$, while it was $30.87 \pm 1.55 \%$ for the same GE-UA concentration (Fig. 2A). The DPPH radical scavenging activity of $150 \mathrm{ppm}$ and $200 \mathrm{ppm}$ GE-BA concentrations increased by more than $50 \%$, than seen at the same concentrations of GE-UA.
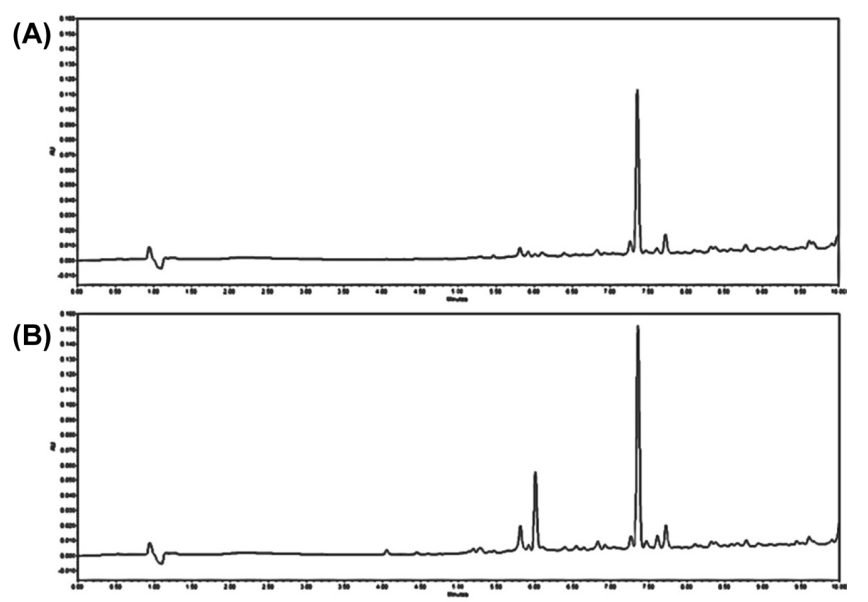

(C)

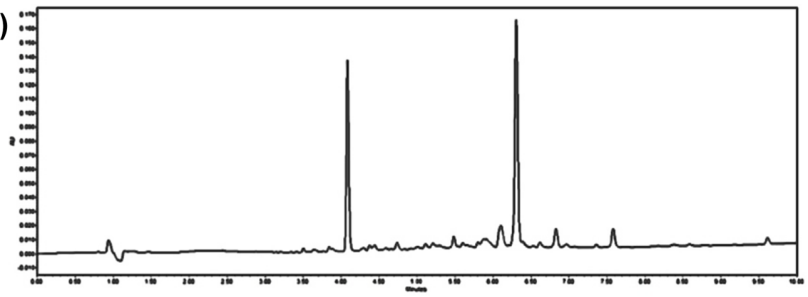

(D)
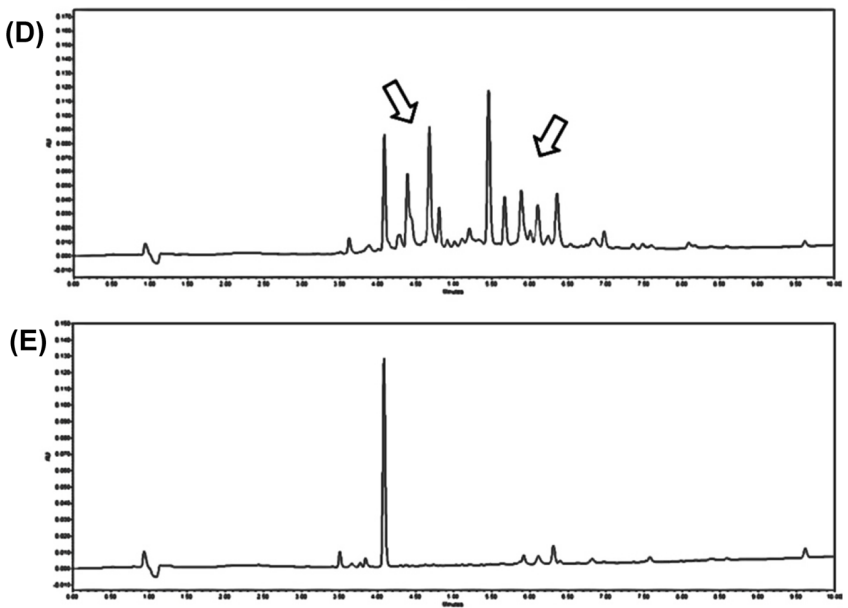

(F)

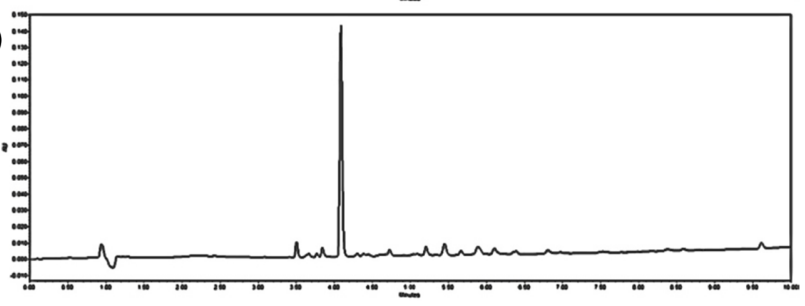

Fig. 1. UPLC profiles of bioconverted Gentiana scabra Bunge. (A) He fraction of non-bioconverted extract at UV $254 \mathrm{~nm}$, (B) He fraction of bioconverted extract at UV $254 \mathrm{~nm},(C)$ EtOAc fraction of nonbioconverted extract at UV $254 \mathrm{~nm}$, (D) EtOAc fraction of bioconverted extract at UV $254 \mathrm{~nm}$, (E) BuOH fraction of non-bioconverted extract at UV $254 \mathrm{~nm}$, (F) BuOH fraction of bioconverted extract at UV $254 \mathrm{~nm}$. Arrows represent new peaks

In addition, ABTS radical scavenging activity was significantly higher at all concentrations. Particularly, GE-BA free-radical scavenging activity was higher $(94.43 \pm 2.42 \%)$ than GE-UA 

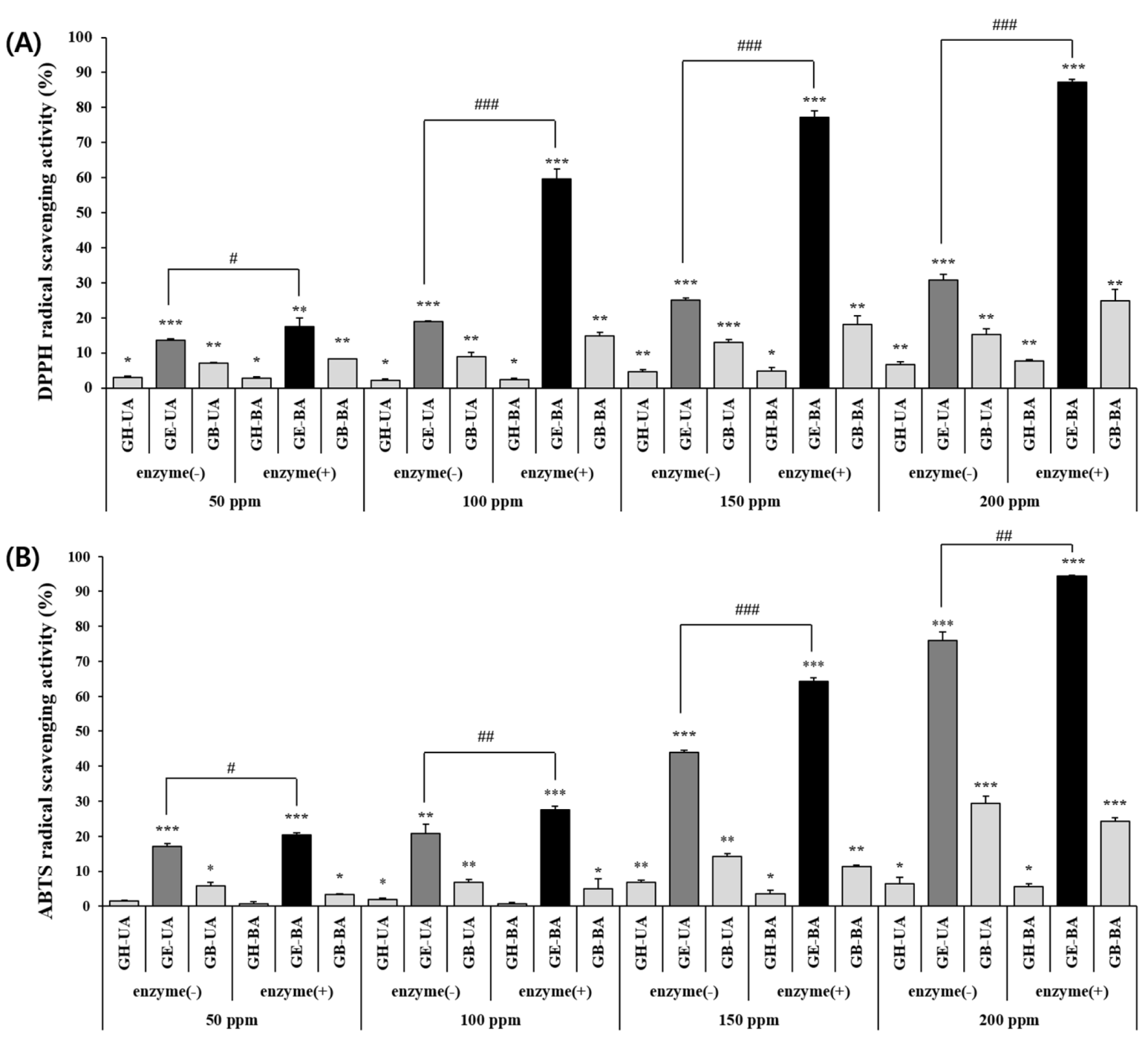

Fig. 2 Anti-oxidant activity of GSB though bioconversion. (A) DPPH radical scavenging activity (B) ABTS radical scavenging activity. All data are presented as means \pm SD. ${ }^{*} p<0.05,{ }^{* *} p<0.01,{ }^{* * *} p<0.001$ compared to control. ${ }^{\#} p<0.05,{ }^{\#} p<0.01,{ }^{\# \#} p<0.001$ compared to bioconversion of the EtOAc fraction

$(75.95 \pm 0.15 \%)$ at a concentration of 200 ppm (Fig. 2B). This evidence indicates that bioconversion increased the anti-oxidant activity of GSB.

\section{Cell viability and NO production}

The effect of GSB on the viability of Raw 264.7 cells is shown in Fig. 3A. Both the bioconverted and the bio-unconverted GSB fractions had similar cell viability as the control group (CNT) at all concentrations tested (10-100 ppm), indicating that GSB had no toxic effect on the RAW 264.7 cells at 10, 25, 50 and 100 ppm (Fig. 3A). As shown in Fig. 3B, at 24 h post exposure, the NO production significantly decreased in a dose-dependent manner after treatment with GE-BA at 10, 25, 50 and $100 \mathrm{ppm}(51.65 \pm$ $3.57,45.66 \pm 4.76,20.15 \pm 7.31$, and $5.85 \pm 7.62 \%$, respectively); however, only a slight decrease was seen after treatment with GE-UA (79.62 $\pm 8.65,84.72 \pm 5.41,79.92 \pm 6.64$, and $79.77 \pm 1.50 \%$, respectively), both being compared to the LPS treated group. Particularly, at $100 \mathrm{ppm}$, GE-BA decreased the NO production by approximately $95 \%$, compared to the LPS-stimulated group. However, the other fractions had no effect on the RAW 264.7 cells.

Effect of bioconversion on the iNOS and COX-2 expression Based on the previous NO production results, the ethyl acetate GSB fraction was selected for further experiments. The effect of GE-BA on LPS-stimulated iNOS and COX-2 protein expression in RAW 264.7 macrophages was evaluated by Western blot analysis. The analysis proceeded after a $24 \mathrm{~h}$ stimulation with LPS $(1 \mu \mathrm{g} / \mathrm{mL})$. As shown in Fig. 4, the expression level of iNOS and COX-2 increased after the LPS treatment. However, GE-BA remarkably inhibited the iNOS and COX-2 protein expressions as compared to GE-UA exposure, in the LPS-stimulated RAW 264.7 

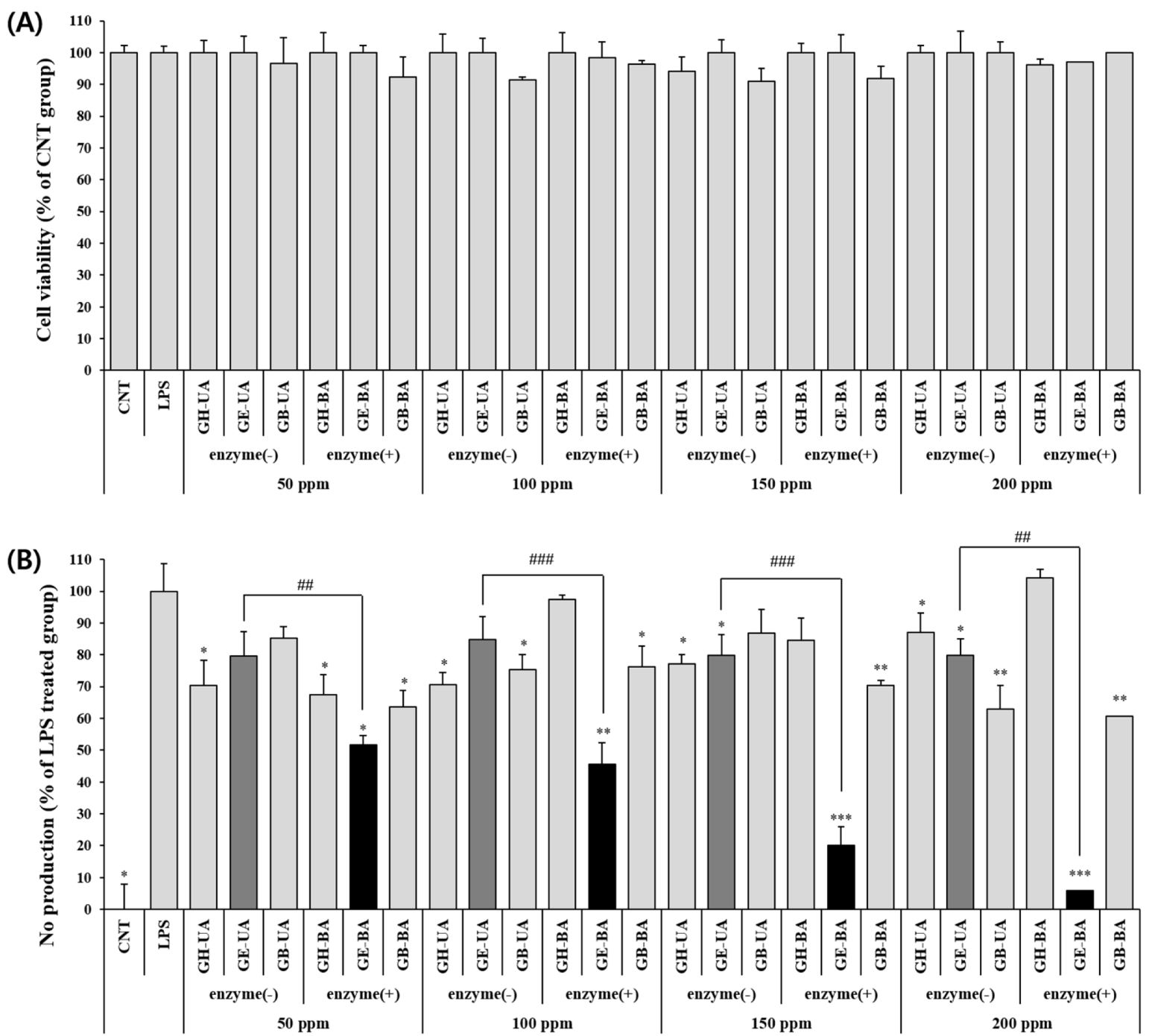

Fig. 3 Anti-inflammatory activity of GSB though bioconversion. (A) cell viability (B) NO production. All data are presented as means \pm SD. $* p<0.05$, ${ }^{* *} p<0.01,{ }^{* *} p<0.001$ compared to control in cell viability. NO production was compared the LPS group. ${ }^{\#} p<0.05,{ }^{* \#} p<0.01,{ }^{\# \# \#} p<0.001$ compared to bioconversion of the EtOAc fraction

cells. Particularly, iNOS and COX-2 proteins expression decreased significantly after treatment with100 ppm GE-BA $(p<0.001)$.

\section{Effect of bioconversion on the MAPK pathway}

The effect of GE-BA on MAP kinases was examined in LPSinduced RAW 264.7 cells. The level of phospho-p38 (p-p38) decreased in the GE-BA-treated cells as compared to the LPS treated group, by $0.61 \pm 0.03$-fold by LPS and $0.55 \pm 0.03$-fold at 50 and 100 ppm, respectively (Fig. 5B). In addition, phospho-JNK (p-JNK) decreased by $0.68 \pm 0.04$-fold at 100 ppm (Fig. 5C). The level of phospho-ERK (p-ERK) dramatically decreased in the GEBA-treated cells than in the LPS group (Fig. 5D) (0.38 \pm 0.03 -fold and $0.19 \pm 0.040$-fold at 50 and $100 \mathrm{ppm}$, respectively). The total ERK, p38 and JNK in the GE-BA treated cells had a tendency to increase as much as the CNT group, while the decrease in the GEUA-treated cells was proportionate to that seen in the LPS group.
In other words, the ethyl acetate fraction of the bioconverted GSB was more inhibitory to the activation and phosphorylation of ERK, p38 and JNK, than the bio-unconverted extract.

\section{Effect of bioconversion on the NF- $\kappa B$ signaling pathway}

RAW 264.7 cells were pretreated with GE-BA and GE-UA (50 and $100 \mathrm{ppm}$ ) for $1 \mathrm{~h}$, after which they cells were stimulated with $1 \mu \mathrm{g} / \mathrm{mL}$ of LPS for $1.5 \mathrm{~h}$. Cells were further incubated with IKK $\alpha$ and I $\kappa \mathrm{B}$ for $24 \mathrm{~h}$ after LPS stimulation. The expression of $\mathrm{NF}-\kappa \mathrm{B}$ was examined in the nuclear and cytoplasmic fractions. The levels of NF- $\kappa B$ increased in the nuclear fractions after $1.5 \mathrm{~h}$ of stimulation with LPS (Fig. 6A). However, treatment with GE$\mathrm{BA}$ decreased the NF- $\kappa \mathrm{B}$ levels in the nuclear fraction in a concentration-dependent manner. I $\mathrm{B}$ and IKK $\alpha$ were examined by Western blot analyses after $24 \mathrm{~h}$ stimulation with LPS. LPS treatment reduced the I $\mathrm{B}$ levels at $24 \mathrm{~h}$. In addition, $100 \mathrm{ppm}$ 


\section{(A)}
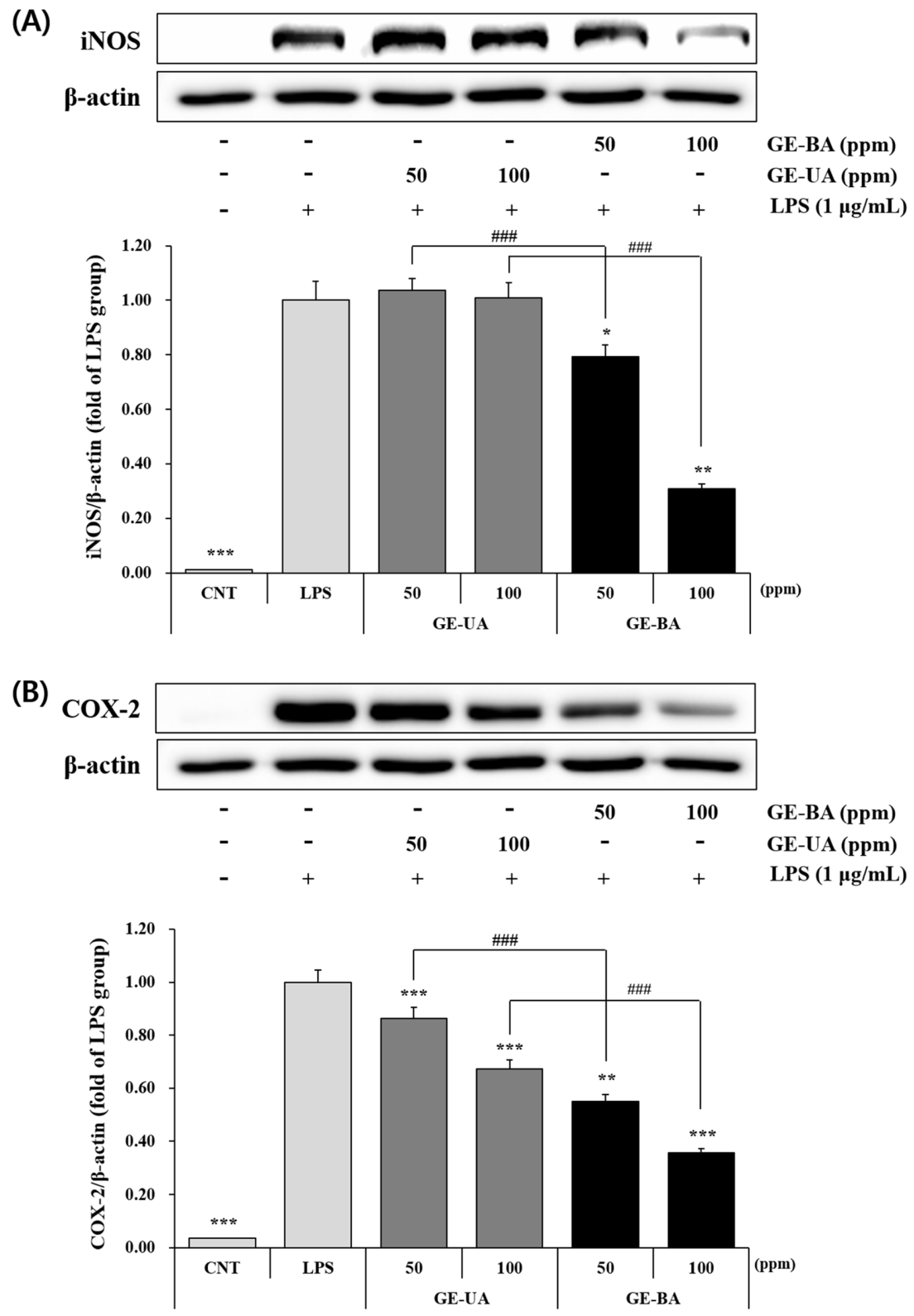

Fig. 4 Effect of GSB's bioconversion on iNOS and COX-2 protein expression. (A) iNOS expression (B) COX-2 expression. All data are presented as means \pm SD. ${ }^{*} p<0.05,{ }^{* *} p<0.01,{ }^{* * *} p<0.001$ compared to LPS group. ${ }^{\#} p<0.05,{ }^{\#} p<0.01,{ }^{\# \#} p<0.001$ compared to bioconversion of the EtOAc fraction

GE-UA concentration also reduced the I $\kappa B$ levels at $24 \mathrm{~h}$. However, GE-BA completely blocked the I $\mathrm{B}$ degradation in a concentration-dependent manner at $24 \mathrm{~h}$. IKK $\alpha$ showed similar results as I $\kappa$ B. After $24 \mathrm{~h}$ LPS stimulation, GE-UA and LPS treatment decreased the IKK $\alpha$ levels, while GE-BA blocked $\mathrm{IKK} \alpha$ degradation. As shown in Fig. $6 \mathrm{C}, \mathrm{p}-\mathrm{I} \kappa \mathrm{B} / \mathrm{I} \kappa \mathrm{B}$ also decreased after LPS stimulation for $15 \mathrm{~min}$.

mRNA expression of iNOS, COX-2 and pro-inflammatory cytokines

RAW 264.7 cells were treated with varying concentrations of GE-
BA and GE-UA (50 and $100 \mathrm{ppm}$ ). The RAW cells were harvested at $24 \mathrm{~h}$ after LPS stimulation, and the levels of the inflammatory cytokines IL-6, IL- $1 \beta$, and TNF- $\alpha$ were measured by RT-PCR. LPS-induction increases the iNOS, COX-2, IL-6, IL$1 \beta$, and TNF- $\alpha$ mRNA levels in RAW 264.7 cells, compared to the CNT group. As shown in Fig. 7B, GE-BA decreased iNOS mRNA expression compared to the LPS group, by $0.51 \pm 0.01$-fold at $100 \mathrm{ppm}$ concentration. In addition, GE-BA remarkably decreased the IL- 6 and IL- $1 \beta$ mRNA expression by $0.30 \pm 0.00$-fold and $0.45 \pm 0.04$-fold at $100 \mathrm{ppm}$, respectively (Fig. 7D, E). Similarly, COX-2 and TNF- $\alpha$ mRNA expression were remarkably decreased 

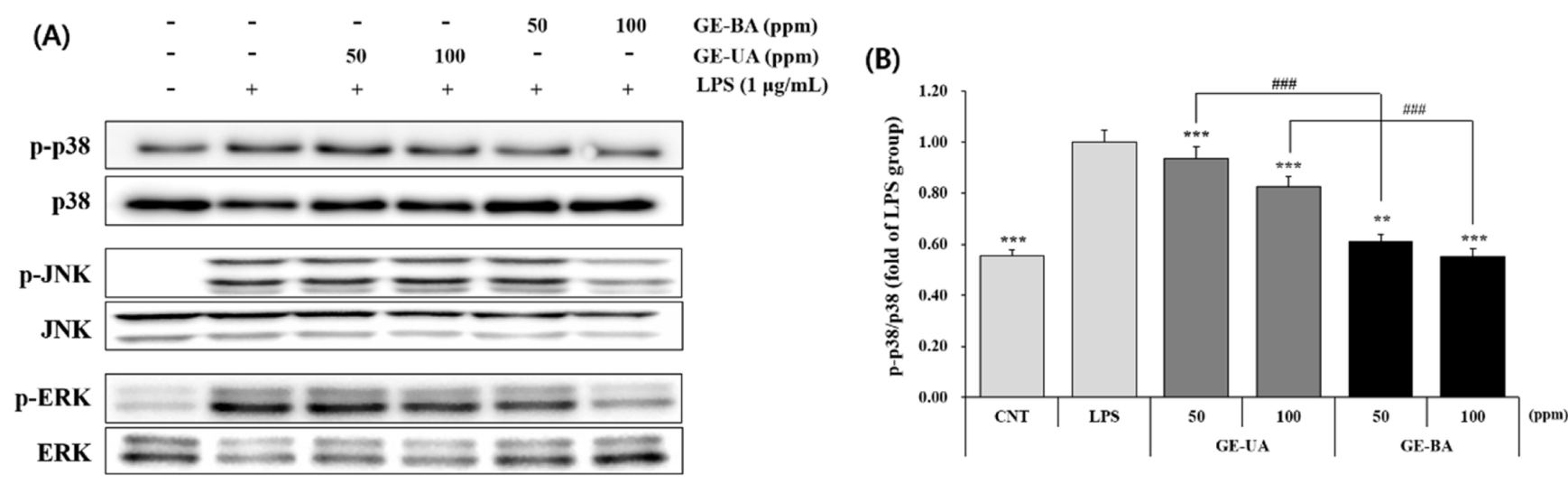

(C)

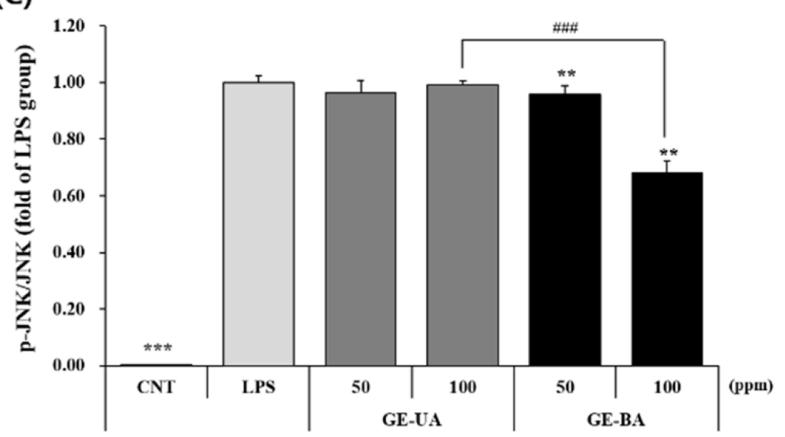

(D)

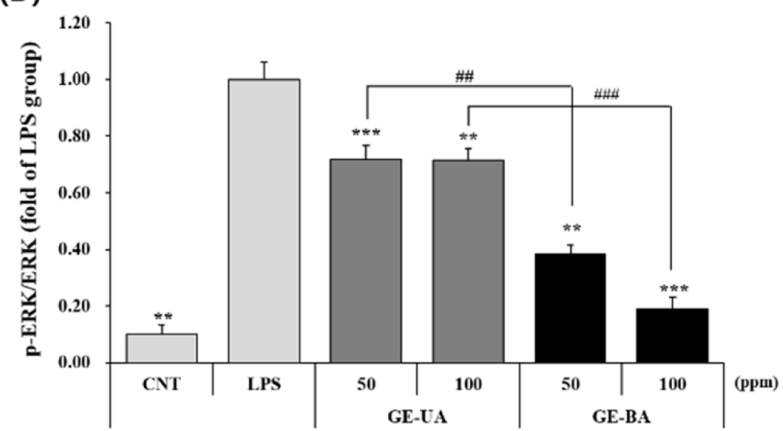

Fig. 5 Effect of GSB's bioconversion on MAP kinases expression. (A) Western blot result of MAP kinases expression (B) expression of p-p38/p38 (C) expression of $\mathrm{p}-\mathrm{JNK} / \mathrm{pJNK}$ (D) expression of $\mathrm{p}-\mathrm{ERK} / \mathrm{pERK}$. All data are presented as means $\pm \mathrm{SD}$. ${ }^{*} p<0.05,{ }^{* *} p<0.01,{ }^{* * *} p<0.001$ compared to LPS group. ${ }^{\#} p<0.05,{ }^{\#} p<0.01,{ }^{\# \#} p<0.001$ compared to bioconversion of the EtOAc fraction

in the $100 \mathrm{ppm}$ GE-BA-treated group as compared to the LPS group, by $0.50 \pm 0.04$-fold and $0.53 \pm 0.030$-fold, respectively (Fig. 7C, F). However, GE-UA had no remarkable effect on the COX2 and TNF- $\alpha$ levels. These results indicate that the inhibition of inflammatory cytokines is enhanced through bioconversion.

\section{Discussion}

The incidence of inflammation, which is relevant in renal, neural, intestinal and pulmonary diseases, has increased in the last decade [36-38]. Recent studies indicate that physiologically active substances such as naringenin, exhibit an anti-nephrotoxic effects by reducing the inflammation and oxidative stress [39]. Moreover, bioconversion mediated increments in the amount of quercetin, the main antioxidant component, enhanced the anti-oxidant activity physiologically [27]. Thus, this study aimed to investigate the improvements in the anti-oxidant and anti-inflammatory activities of GSB through bioconversion, using crude enzyme extract of $A$. kawachii that belongs to the glycosyl hydrolase family [40].

GSB contains bioactive components such as gentiopicroside and swertiamarin, which are well-known glycosides [41].

In the UPLC profile, the ethyl acetate GSB fractions showed unknown and increased peaks after bioconversion, compared with that of the untreated or inactivated crude enzyme treated fraction. This could be associated with glycosyl hydrolase from $A$. kawachii, which shows hydrolytic activity toward laminarin, a polysaccharide from seaweed $[42,43]$. Thus, more compounds might be converted by an enzymatic reaction. Further studies are underway to confirm these results.

Free radicals, including ROS, are molecules containing one or two unpaired electrons that cause damage to tissues and cells. Excess free radicals lead to acute and chronic oxidative stress, resulting in various diseases through oxidized reactions with amino acids, fatty acids, and other bio-macromolecular compounds. However, free radicals are scavenged by antioxidants such as flavonoids, phenolic compounds, vitamin $\mathrm{E}$ and rutin [44]. The DPPH assay, which is a simple and stable method, is based on electron and hydrogen transfers. When DPPH radical is scavenged by hydrogen or an electron-donating molecule, absorbance is decreased [45]. However, ABTS assay acts by decolorizing the ABTS cation radical $\left(\mathrm{ABTS}^{+}\right)$when an antioxidant is present [28]. The DPPH and ABTS radical scavenging activity by phenols, which have high antioxidant activity, yield the same results [46]. Bioconversion using lactic acid fermentation increased the free radical scavenging activity of mulberry juice by improveng phenolic and flavonoid constituents [47].

In our study, the ethyl acetate fraction GSB increased the DPPH 
(A)

$\begin{array}{ccccccl}- & - & - & - & 50 & 100 & \text { GE-BA }(p p m) \\ - & - & 50 & 100 & - & - & \text { GE-UA }(p p m) \\ - & + & + & + & + & + & \text { LPS }(1 \mu \mathrm{g} / \mathrm{mL})\end{array}$

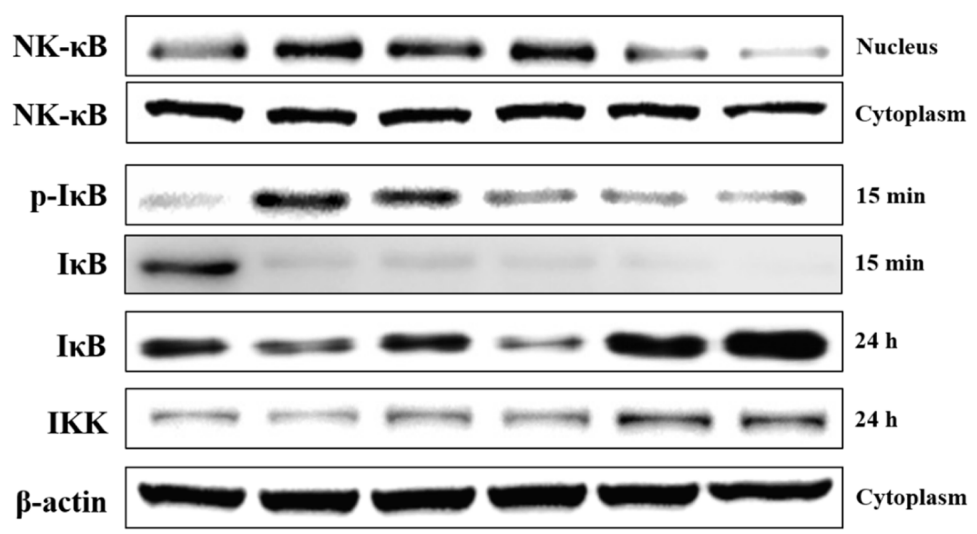

(B)

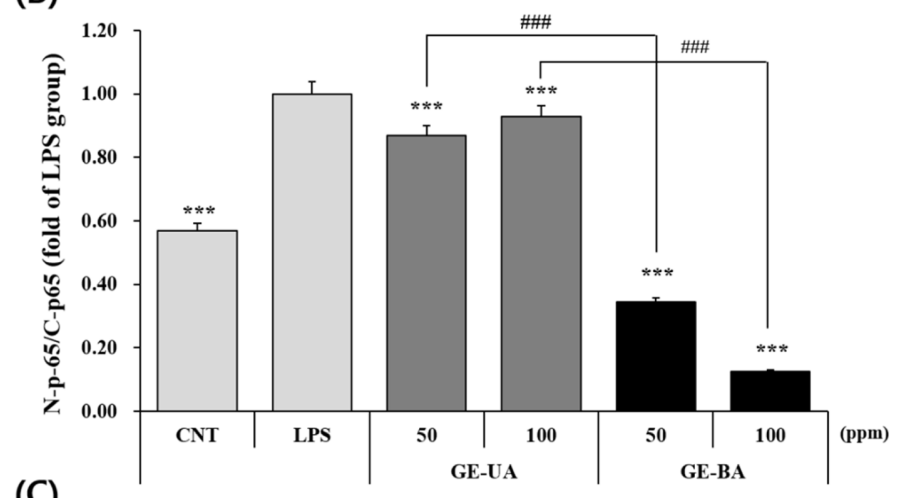

(C)

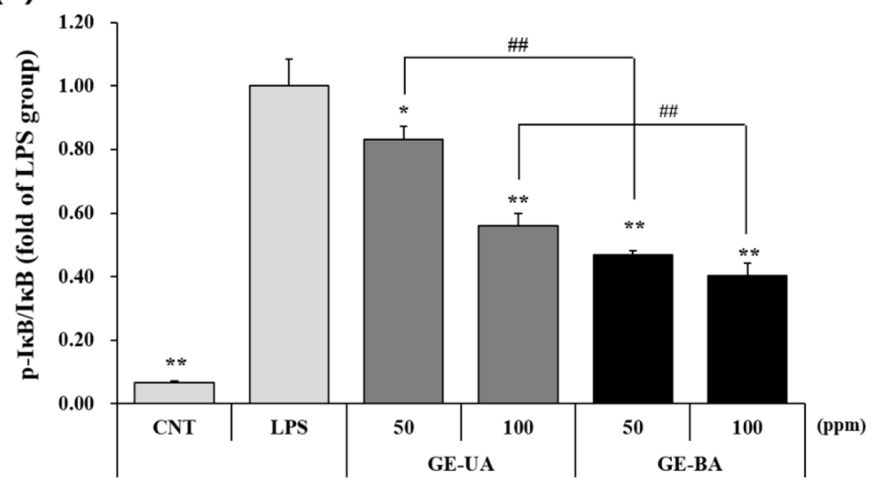

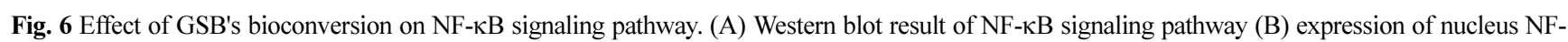
$\kappa \mathrm{B} /$ cytoplasm NF- $\kappa \mathrm{B}(\mathrm{C})$ expression of $\mathrm{p}-\mathrm{I} \kappa \mathrm{B} / \mathrm{I} \kappa \mathrm{B}$. All data are presented as means $\pm \mathrm{SD}$. ${ }^{*} p<0.05,{ }^{* *} p<0.01,{ }^{* * *} p<0.001$ compared to LPS group. ${ }^{\#} p<0.05,{ }^{\# \#} p<0.01,{ }^{\# \#} p<0.001$ compared to bioconversion of the EtOAc fraction

and ABTS radical scavenging activity; especially, there was a remarkable increase in the antioxidant activity of the ethyl acetate fraction of $A$. kawachii-bioconverted GSB (GE-BA) than in the $A$. kawachii-untreated GSB (GE-UA) ethyl acetate fraction. These results indicate that the transformation of GSB compounds caused by bioconversion using $A$. kawachii crude enzyme increased their anti-oxidant activity.
NO is a free radical that reacts with oxygen radicals and is synthesized by NOS. Low levels of NO are regulatory in their effects, such as in tumorigenesis and wound repair, etc. However, high levels of NO contribute to DNA damage, cytotoxicity, oxidative and nitrosative stress. NOS has three isoforms, including neuronal NO synthase, inducible NO synthase (iNOS), and endothelial NO synthase. Overproduction of NO results in higher 

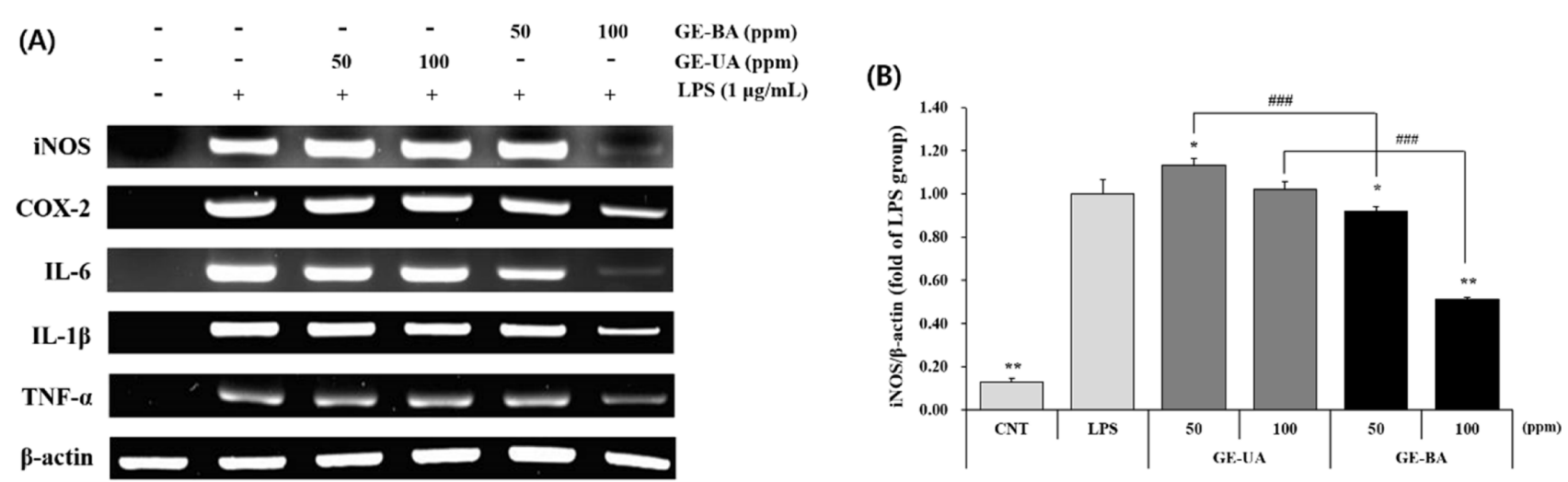

(C)
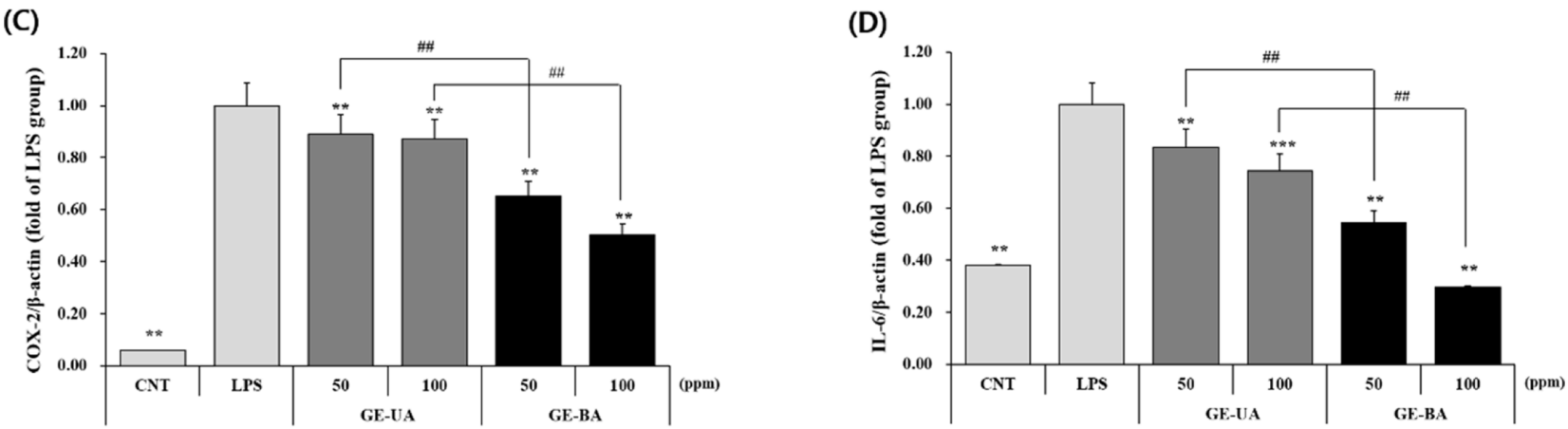

(E)

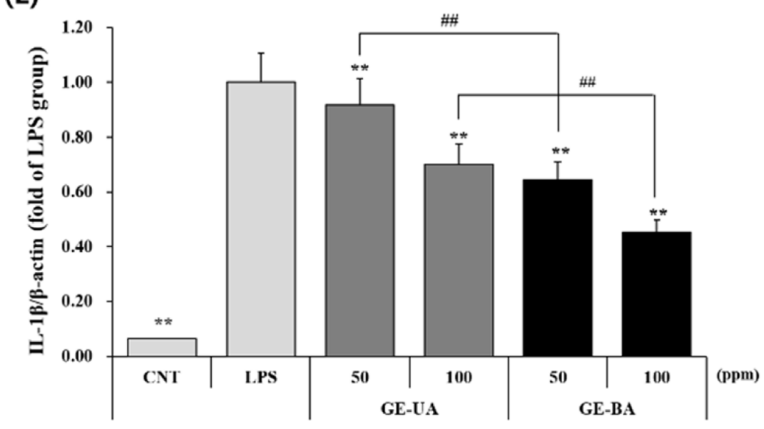

(F)

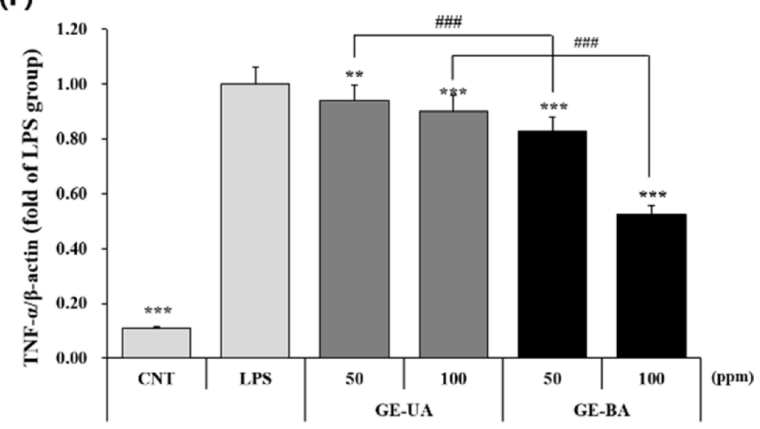

Fig. 7 Effect of GSB's bioconversion on Pro-inflammatory cytokines mRNA expression. (A) electrophoresis result of pro-inflammatory cytokines mRNA expression (B) expression of iNOS/ $\beta$-actin (C) expression of COX-2/ $\beta$-actin (D) expression of IL-6/ $\beta$-actin (E) expression of IL-1 $/ \beta / \beta$-actin (F) expression of TNF- $\alpha / \beta$-actin. All data are presented as means $\pm \mathrm{SD} .{ }^{*} p<0.05,{ }^{* *} p<0.01,{ }^{* * *} p<0.001$ compared to LPS group. ${ }^{\#} p<0.05$, ${ }^{*} p<0.01$, ${ }^{2 \# \#} p<0.001$ compared to bioconversion of the EtOAc fraction

production of iNOS, which is highly expressed during inflammation. iNOS regulates the inflammatory cytokines such as IL-1 $\beta$ and TNF- $\alpha$ [6,48]. Likewise, COX catalyzes the biosynthesis of prostaglandins, which are involved in edema, inflammation, and tumors from arachidonic acid, and has two isoforms: COX-1 and COX-2. $[48,49]$. NO production as well as iNOS and COX-2 expression increase after stimulation with LPS [50-52]. Also, previous studies have reported that iNOS and COX-2 expression were suppressed by bioactive substance $[31,32]$.

This study also found that GE-BA inhibited the COX-2 expression, while LPS treatment increased it. In addition, NO production and iNOS expression were increased after stimulation with LPS, while GE-BA remarkably decreased the expression of both isoforms. These results suggest that low-level NO led to a reduction in iNOS expression, and this effect was enhanced through bioconversion.

MAP kinases (including ERK, JNK and p38) are activated by various stimuli, including inflammation, osmotic shock, apoptosis and oxidative stress [16,53]. These MAP kinases rapidly increase after LPS stimulation for 10-30 $\mathrm{min}$ [54]. Obesity activates MAP kinases, while quercetin suppresses their phosphorylation [13]. In this study, we observed that LPS increased the expression of MAP kinases. However, GE-BA treatment inhibited the activation and phosphorylation of MAP kinases, including ERK, JNK, and p38.

Activation of $\mathrm{p} 38$ is related to NF- $\kappa \mathrm{B}$ signaling [55]. NF- $\kappa \mathrm{B}$ is a major transcription factor for the expression of pro-inflammatory 
mediators such as iNOS, COX-2, and IL-1 $\beta$, when stimulated by LPS $[56,57]$. Inactive NF- $\kappa \mathrm{B}$ combines with $\mathrm{I} \kappa \mathrm{B}$, and is present in the cytoplasm. The IKK $\alpha$ complex, which induces the phosphorylation of $\mathrm{I} \kappa \mathrm{B}$ and $\mathrm{NF}-\kappa \mathrm{B}$, translocates to the nucleus and regulates the transcription of iNOS and COX-2 [18,58]. LPS stimulation remarkably increases the phosphorylation of IKK $\alpha$, with an equivalent increase in the phosphorylation and degradation of I $\mathrm{B}$ [59]. Finally, activated NF- $\kappa \mathrm{B}$ increases the production of inflammatory cytokines [57]. According to a study by Hu TY [60] bioactive component such as xanthone was decreased phosphorylation of NF- $\mathrm{KB}$.

In the present study, we found that LPS stimulation led to the accumulation of NF- $\kappa B$ in the nucleus, which may be due to the translocation of NF- $\kappa \mathrm{B}$ from the cytoplasm to the nucleus. In GEBA-treated cells, the level of NF- $\kappa B$ significantly decreased in the nucleus. Furthermore, the level of IKK $\alpha$ and IאB (at $24 \mathrm{~h}$ ) inhibited the phosphorylation and degradation, as compared to GE-UA. This result suggests that GE-BA blocked the LPS stimulated IKK $\alpha$ phosphorylation and inhibited the I $\mathrm{B}$ degradation. Eventually, GE-BA inhibited the traslocation of NF- $\kappa \mathrm{B}$ from the cytoplasm to the nucleus. As a result, we also observed that GEBA inhibited the mRNA expression of inflammatory cytokines, such as iNOS, COX-2, TNF- $\alpha$, IL-6, and IL-1 $\beta$. Our study indicates that bioconversion, which involves the enzymatic activity of $A$. kawachii crude enzyme on GSB, decreases the production of inflammatory mediators through IKK $\alpha, \mathrm{I} \kappa \mathrm{B}$, and NF- $\kappa \mathrm{B}$ signaling pathways in RAW 264.7 cells, than in the A. kawachii crude enzyme-untreated groups.

In summary, we propose that the ethyl acetate fraction of GSB enhances anti-oxidant and anti-inflammatory activities through the A. kawachii crude enzyme mediated bioconversion. Specifically, the anti-inflammatory activity is associated with the inhibition of MAP kinases and the NF- $\kappa B$ signaling pathway. As a result, the iNOS, COX-2, and inflammatory cytokines were remarkably reduced. These findings suggest that bioconversion of GSB with A. kawachii crude enzyme may have potential benefits for the treatment of inflammation and related oxidative stress diseases.

\section{References}

1. Dorward DA, Lucas CD, Rossi AG, Haslett C, Dhaliwal K (2012) Imaging inflammation: Molecular strategies to visualize key components of the inflammatory cascade, from initiation to resolution. Pharmacol Ther 135: 182-199

2. Li S, Wang Y, Zhao M, Wu J, Peng S (2015) BPIC: A novel anti-tumor lead capable of inhibiting inflammation and scavenging free radicals. Bioorg Med Chem Lett 25: 1146-1150

3. Daabis RG, Rehem RNA, Hassan MM, Khalil GI (2016) Hypogonadism in patients with chronic obstructive pulmonary disease: relationship with airflow limitation, muscle weakness and systemic inflammation. Alexandria Univ Facul Med 52: 27-33

4. Westermann D, Van Linthout S, Dhayat S, Dhayat N, Schmidt A, Noutsias M, Song XY, Spillmann F, Riad A, Schultheiss HP, Tschope C (2007) Tumor necrosis factor-alpha antagonism protects from myocardial inflammation and fibrosis in experimental diabetic cardiomyopathy. Basic Res Cardiol 102: 500-507

5. Wang F, Ma J, Wang KS, Mi C, Lee JJ, Jin X (2015) Blockade of TNF$\alpha$-induced NF- $\mathrm{B}$ signaling pathway and anti-cancer therapeutic response of dihydrotanshinone I. Int Immuno 25: 764-772

6. Vannini F, Kashfi K, Nath N (2015) The dual role of iNOS in cancer. Redox Biol 6: 334-343

7. Maskrey BH, Megson IL, Whitfield PD, Rossi AG (2011) Mechanisms of resolution of inflammation a focus on cardiovascular disease. Arterioscler Thromb Vasc Biol 31: 1001-1006

8. Lepetsos P, Papavassiliou AG (2016) ROS/oxidative stress signaling in osteoarthritis. Biochim Biophy Acta 1862: 576-591

9. Yang RL, Shi YH, Hao G, Li W, Le GW (2008) Increasing oxidative stress with progressive hyperlipidemia in human. J clin Biochem Nutr 43: $154-158$

10. Zhou J, Xu G, Bai Z, Li K, Yan J, Li F, Ma S, Xu H, Huang K (2015) Selenite exacerbates hepatic insulin resistance in mouse model of type 2 diabetes through oxidative stress-mediated JNK pathway. Toxicol Appl Pharm 289: 409-418

11. Wang SW, Yang SG, Liu W, Zhang YX, Xu PX, Wang T, Liu RT (2016) Alpha-tocopherol quinine ameliorates spatial memory deficits by reducing beta-amyloid oligomers, neuroinflammation and oxidative stress in transgenic mice with Alzheimer's disease. Behav Brain Res 296: 109-117

12. Zo J, Feng D, Ling WH, Duan RD (2013) Lycopene suppresses proinflammatory response in lipopolysaccharide-stimulated macrophages by inhibiting ROS-induced trafficking of TLR4 to lipid raft-like domains. J Nutr Biochem 24: 1117-1122

13. Seo MJ, Lee YJ, Hwang JH, Kim KJ, Lee BY (2015) The inhibitory effects of quercetin on obesity and obesity-induced inflammation by regulation of MAPK signaling. J Nutr Biochem 26: 1308-1316

14. Liu D, Perkins JT, Hennig B (2016) EGCG prevents PCB-126-induced endothelial cell inflammation via epigenetic modifications of NF- $\mathrm{BB}$ target genes in human endothelial cells. J Nutr Biochem 28: 164-170

15. Lee JY, Oh TH, Yune TY (2011) Ghrelin inhibits hydrogen peroxideinduced apoptotic cell death of oligodendrocytes via ERK and p38 MAPK signaling. Endoc 152: 2377-2386

16. Hao Y, Liu C, Huang J, Gu Y, Li H, Yang Z, Li R (2016) Ghrelin protects against depleted uranium-induced apoptosis of MC3T3-E1 cells through oxidative stress-mediated p38-mitogen-activated protein kinase pathway. Toxicol appl pharm 290: 116-125

17. Peng J, Lv YC, He PP, Tang YY, Xie W, Liu XY, Shi JF (2015) Betulinic acid down regulates expression of oxidative stress-induced lipoprotein lipase via the PKC/ERK/c-Fos pathway in RAW264. 7 macrophages. Bioch 119: 192-203

18. Fu J, Shi Q, Song X, Xia X, Su C, Liu Z, Song Y (2016) Tetrachlorobenzoquinone exhibits neurotoxicity by inducing inflammatory responses through ROS-mediated IKK/I $\mathrm{B} / \mathrm{NF}-\kappa \mathrm{B}$ signaling. Envir Toxicol Pharm 41: 241-250

19. Wang Z, Wang C, Su T, Zhang J (2014) Antioxidant and immunological activities of polysaccharides from Gentiana scabra Bunge roots. Carbo Polym 112: 114-118

20. Wang C, Wang Y, Zhang J, Wang Z (2014) Optimization for the extraction of polysaccharides from Gentiana scabra Bunge and their antioxidant in vitro and anti-tumor activity in vivo. J Tai Inst Chem Engineers 45: 1126-1132

21. Kakuda R, Iijima T, Yaoita Y, Machida K, Kikuchi M (2002) Triterpenoids from Gentiana scabra. Phytochem 59: 791-794

22. Kim JA, Son NS, Son JK, Jahng Y, Chang HW, Jang TS, Lee SH (2009) Two new secoiridoid glycosides from the rhizomes of Gentiana scabra Bunge. Arch Pharm Res 32: 863-867

23. Cai W, Xu H, Xie L, Sun J, Sun T, Wu X, Fu Q (2016) Purification, characterization and in vitro anticoagulant activity of polysaccharides from Gentiana scabra Bunge roots. Carbo Polym 140: 308-313

24. Palmerín-Carreño DM, Rutiaga-Quiñones OM, Calvo JV, Prado- 
Barragán A, Huerta-Ochoa S (2015) Screening of microorganisms for bioconversion of (+)-valencene to (+)-nootkatone. LWT-Food Sci Tech 64: 788-793

25. Riou C, Salmon JM, Vallier MJ, Günata Z, Barre P (1998) Purification, characterization, and substrate specificity of a novel highly glucosetolerant $\beta$-glucosidase from Aspergillus oryzae. Appl Environ Microbiol 64: 3607-3614

26. Kan SC, Zang CZ, Yeh CW, Chang WF, Lin CC, Hung TH, Liu YC (2015) Enhanced bioconversion rate and released substrate inhibition in (R)-phenylephrine whole-cell bioconversion via partial acetone treatment. Enzy Microb Technol 86: 34-38

27. Yang EJ, Kim SI, Park SY, Bang HY, Jeong JH, So JH, Song KS (2012) Fermentation enhances the in vitro antioxidative effect of onion (Allium сера) via an increase in quercetin content. Food Chem Toxicol 50: 2042-2048

28. Blois MS (1958) Antioxidant determination by the use of a stable free radical. Nature 26: 1198-1200

29. Re R, Pellegrini N, Proteggente A, Pannala A, Yang M, Rice-Evans C (1999) Antioxidant activity applying an improved ABTS radical cation decolorization assay. Free Radic Biol Med 26: 1231-1237

30. Hsu CL, Fang SC, Liu CW, Chen YF (2013) Inhibitory effects of new varieties of bitter melon on lipopolysaccharide-stimulated inflammatory response in RAW 264.7 cells. J Func Food 5: 1829-1837

31. Kim H, Youn K, Yun EY, Hwang JS, Jeong WS, Ho CT, Jun M (2015) Oleic acid ameliorates $A \beta$-induced inflammation by downregulation of COX-2 and iNOS via NFKB signaling pathway. J Func Food 14: 1-11

32. Park EJ, Cheenpracha S, Chang LC, Pezzuto JM (2011) Suppression of cyclooxygenase-2 and inducible NOS expression by epimuqubilin A via $\mathrm{IKK} / \mathrm{I \kappa B} / \mathrm{NF}-\kappa \mathrm{B}$ pathways in lipopolysaccharide-stimulated RAW 264.7 cells. Phytochem Lett 4: 426-431

33. Wann AKT, Chapple JP, Knight MM (2014) The primary cilium influences interleukin-1 $\beta$-induced NF- $\mathrm{BB}$ signalling by regulating IKK activity. Cellular Signal 26: 1735-1742

34. Heo SJ, Yoon WJ, Kim KN, Ahn GN, Kang SM, Kang DH, Affan A, Oh C, Jung WK, Jeon YJ (2010) Evaluation of anti-inflammatory effect of fucoxanthin isolated from brown algae in lipopolysaccharidestimulated RAW 264.7 macrophages. Food and Chem Toxi 48: 20452051

35. Floegel A, Kim DO, Chung SJ, Koo SI, Chun OK (2011) Comparison of ABTS/DPPH assays to measure antioxidant capacity in popular antioxidant-rich US foods. J Food Comp Analy 24: 1043-1048

36. Lafferty EI, Qureshi ST, Schnare M (2010) The role of toll-like receptors in acute and chronic lung inflammation. J Inflam 7: 1-14

37. Wu KL, Chan SH, Chan JY (2012) Neuroinflammation and oxidative stress in rostral ventrolateral medulla contribute to neurogenic hypertension induced by systemic inflammation. J Neuroinfla 9: 1-15

38. Chesnokova V, Pechnick RN, Wawrowsky K (2016) Chronic peripheral inflammation, hippocampal neurogenesis, and behavior. Brain Behav Immun 58: 1-8

39. Karuppagounder V, Arumugam S, Thandavarayan RA, Pitchaimani V, Sreedhar R, Afrin R, Ueno K (2015) Naringenin ameliorates daunorubicin induced nephrotoxicity by mitigating AT1R, ERK1/2-NFKB p65 mediated inflammation. Int Immuno 28: 154-159

40. Henrissat B, Bairoch A (1993) New families in the classification of glycosyl hydrolases based on amino acid sequence similarities. Biochem J 293: 781-788

41. Singh A (2008) Phytochemicals of Gentianaceae: a review of pharmacological properties. Int J Pharma Sci Nanotec 1: 33-36

42. Zeng W, Han H, Tao Y, Yang L, Wang Z, Chen K (2013) Identification of bio-active metabolites of gentiopicroside by UPLC/Q-TOF MS and NMR. Biomed Chroma 27: 1129-1136

43. Koseki T, Mese Y, Fushinobu S, Masaki K, Fujii T, Ito K, Iefuji H (2008) Biochemical characterization of a glycoside hydrolase family 61 endoglucanase from Aspergillus kawachii. Appl Micro Biotec 77: 1279
1285

44. Wojtunik-Kulesza KA, Oniszczuk A, Oniszczuk T, WaksmundzkaHajnos M (2016) The influence of common free radicals and antioxidants on development of Alzheimer's Disease. Biomed Pharm 78: $39-49$

45. Jabbari M, Jabbari A (2016) Antioxidant potential and DPPH radical scavenging kinetics of water-insoluble flavonoid naringenin in aqueous solution of micelles. Colloid Surf A: Physical Engineer Aspects 489: 392-399

46. Lou H, Hu Y, Zhang L, Sun P, Lu H (2012) Nondestructive evaluation of the changes of total flavonoid, total phenols, ABTS and DPPH radical scavenging activities, and sugars during mulberry (Morus alba L.) fruits development by chlorophyll fluorescence and RGB intensity values. LWT-Food Sci Techno 47: 19-24

47. Kwaw E, Ma Y, Tchabo W, Apaliya MT, Wu M, Sacle Sackey A, Xiao L, Tahir HE (2018) Effect of lactobacillus strains on phenolic profile, color attributes and antioxidant activities of lactic -acid-fermented mulberry juice. Food Chem 250: 148-154

48. Lai CS, Lee JH, Ho CT, Liu CB, Wang JM, Wang YJ, Pan MH (2009) Rosmanol potently inhibits lipopolysaccharide-induced iNOS and COX-

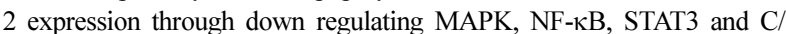
EBP signaling pathways. J Agri Food Chem 57: 10990-10998

49. Dannenberg AJ, Lippman SM, Mann JR, Subbaramaiah K, DuBois RN (2005) Cyclooxygenase-2 and epidermal growth factor receptor: pharmacologic targets for chemoprevention. J Clin Oncol 23: 254-266

50. Nahar PP, Driscoll MV, Li L, Slitt AL, Seeram NP (2014) Phenolic mediated anti-inflammatory properties of a maple syrup extract in RAW 264.7 murine macrophages. J Func Foods 6: 126-136

51. Xiong H, Cheng Y, Zhang X, Zhang X (2014) Effects of taraxasterol on iNOS and COX-2 expression in LPS-induced RAW 264.7 macrophages. J Ethnopharm 155: 753-757

52. Lee J, Tae N, Lee JJ, Kim T, Lee JH (2010) Eupatolide inhibits lipopolysaccharide-induced COX-2 and iNOS expression in RAW264. 7 cells by inducing proteasomal degradation of TRAF6. Eur J Pharm 636: 173-180

53. Yokota T, Wang Y (2016) p38 MAP kinases in the heart. Gene 575: 369-376

54. Park EJ, Shen L, Sun D, Pezzuto JM (2013) Inhibitory effect of a callophycin A derivative on iNOS expression via inhibition of Akt in lipopolysaccharide-stimulated RAW 264.7 cells. J Nat Prod 77: 527-535

55. Pasquali MAB, Gelain DP, Zeidán-Chuli F, Pires AS, Gasparotto J, Terra SR, Moreira JCF (2013) Vitamin A (retinol) down regulates the receptor for advanced glycation endproducts (RAGE) by oxidant-dependent activation of p38 MAPK and NF- $\kappa$ B in human lung cancer A549 cells. Cell Signal. 25: 939-954

56. Zhang TZ, Yang SH, Yao JF, Du J, Yan TH (2015) Sangxingtang inhibits the inflammation of LPS-induced acute lung injury in mice by downregulating the MAPK/NF- $\mathrm{B}$ pathway. Chin J Nat Med 13: 889-895

57. Ma JQ, Li Z, Xie WR, Liu CM, Liu SS (1998) Quercetin protects mouse liver against $\mathrm{CCl}$ 4-induced inflammation by the TLR2/4 and MAPK/ NF- $\kappa$ B pathway. Int Immun 28: 531-539

58. Lee JI, Burckart GJ (1998) Nuclear factor kappa B: important transcription factor and therapeutic target. J Clin Pharm 38: 981-993

59. Zeng KW, Yu Q, Song FJ, Liao LX, Zhao MB, Dong X, Tu PF (2015) Deoxysappanone $\mathrm{B}$, a homo isoflavone from the Chinese medicinal plant Caesalpinia sappan L., protects neurons from microglia-mediated inflammatory injuries via inhibition of IêB kinase (IKK)-NF- $\mathrm{B}$ and p38/ERK MAPK pathways. Eur J Pharm 748: 18-29

60. Hu TY, Ju JM, Mo LH, Ma L, Hu WH, You RR, Chen XQ, Chen YY, Liu ZQ, Qiu LZ, Qiu SQ, Fan JT, Cheng BH (2019) Anti-inflammation action of xanthones from Swertia chirayita by regulating $\mathrm{COX}-2 / \mathrm{NF}-\kappa \mathrm{B} /$ MAPKs/AKt signaling pathways in RAW 264.7 macrophage cells. Phytomed 55: 214-221 